\title{
Breastfeeding Pattern among Saudi Arabian Women, Hafr Al- Batin City
}

\author{
Asmaa Ghareeb Mohamed ${ }^{1}$, Reda Mhmoud Hables ${ }^{2}$ \\ ${ }^{I}$ Assistant prof. of Community Health Nursing, Faculty of Nursing, Assiut University, Egypt \\ Associate prof. Nursing Department (CAMS), Hafr Al-Batin University, KSA \\ ${ }^{2}$ Lecturer of Obstetric \& Gynecological Nursing, Faculty of Nursing, Alexandria University, Egypt \\ Assistant prof. Nursing Department (CAMS), Hafr Al- Batin University, KSA
}

\begin{abstract}
Breastfeeding (BF) is the normal way of providing young infants with the nutrients needs for healthy growth and development. The World Health Organization (WHO) recommends that infants be exclusively breastfed for the first six months, followed by breastfeeding along with complementary foods for up to two years of age or beyond.

Aim: this study aimed to assess the Saudis women practices towards breast feeding and determine factors associated with low rate of breastfeeding.

Methods: Descriptive explanatory study design was used. Three parts structured interview questionnaire was developed to collect information about socio- demographic data, history of previous breast feeding and causes of lack of breastfeeding. A total sample of 193 women who agreed to participate in the study was collected from shopping malls.

Results: The study results show that the mean age was $(33 \pm 5.73)$, and $70.5 \%$ of respondents had a university education. More than one half (52.5\%) of them initiate breastfeeding early hours after labor and nearly one third (29.7\%) of them continuing breastfeeding for one month. The findings also revealed that (49.5\%) of participants stated that insufficient breast milk was the cause for lack breastfeeding.

Conclusion: It was concluded that (71.3\%) of Saudi-women breastfed their babies less than six months of age and the most mentioned causes for lack breastfeeding were insufficient milk, pain/illness and work conditions. Recommendations: a planned health education campaigns should be directed to improve Saudi women practices towards breast feeding.
\end{abstract}

Keywords: Breast feeding, Practices, Saudi-women

\section{Introduction}

Breastfeeding has generally considered by health professionals as the ideal feeding practice for infants. It is the first communication channel between the mother and her baby. (World Health Organization, WHO, 2015) described breastfeeding as an unequaled way of providing ideal food for the healthy growth and development of infants. Optimal breastfeeding of infants under two years of age has the greatest potential impact on child survival of all preventive interventions, with the potential to prevent over 800,000 deaths (13 per cent of all deaths) in children under five in the developing world. (Lancet, 2013)

Superiority of breast milk compared to other types of milk for the nourishment of the human infant offering better health benefits, has been established by various research publications. All the nutritional needs for most of these children are provided by breast milk in a proper amounts and duration. Also, providing the needed nutrition for the babies, boosting the baby's immune system, helping mothers to lose weight after pregnancy, and stimulating the uterus to return to its previous position before pregnancy. In addition, infants can absorb and digest breast milk more easily than baby formula.(wayna,2006)

Many communities in the modern times recognize the need for promoting breastfeeding and this has resulted in encourage women to stick to breastfeeding for as long as possible or it is include the religious groups that even use the verses from the holy books to prove to their listeners the importance of breastfeeding. Case in point, some Muslim leaders have quoted the Quran a verse that says that god has ordered women to ensure that they breastfeed their children for two years (Almoud, 2013).

Breastfeeding has also been viewed as a natural phenomenon that enables mothers to express their love, desire to protect their children, and tenderness towards them. (Binns etal, 2014) Health organizations such as WHO, UNICEF have been on the frontline advocating about breastfeeding should be exclusively done for the first six months and once a child starts weaning, it should be continued to at least two years.. While this situation is perfectly normal for international health bodies, there are some special cases whereby mothers have refused to breastfeed exclusively for six months and even refused to continue the process for two years. This is wrong as there are numerous benefits associated with breastfeeding and the breast milk for both the mother and the child. (United Nations Children Fund, 2008, Bamgboye etal, 2011). 
In Saudi Arabia there has been a considerable change in the pattern of breastfeeding in recent decades due to population transition as a result of advancements in socioeconomic status.

(WBTi, 2012) There is insufficient data available on breastfeeding in Saudi Arabia to monitor progress and develop promotion programs. WHO does not report any breastfeeding data in the country profile because there are no national data on breastfeeding (MOH, 2010 \& WHO 2010).

In Middle Eastern countries, especially in Islamic societies, it should be noted that breastfeeding has a religious basis. Mothers continue to nurse their children for at least two years (Musaiger, 1995). However, modernization as well as the aggressive promotion and marketing campaigns of infant formula and other baby food have influenced the traditions of breastfeeding. This resulted in the increased use of bottle-feeding, and mothers ignored the Quranic recommendations of breastfeeding for two years (Harfouche, $1982 \&$ Balo etal, 1996).

\section{Statement of the problem:}

Breast milk is the best food for a child; it has no substitute especially for children less than six month of age. Lack of optimal breastfeeding can lead to malnutrition, often leading to occurrence of many diseases in children and even death. Studies from Saudi Arabia have recorded a progressive decline in breastfeeding practice and duration, especially among young mothers) so, breastfeeding is an important topic in health education because of the many benefits that can be gained for babies, mothers, and communities.

\section{This study aimed to:}

1- Assess breastfeeding practices among Saudi women at Hafr Al-Batin city.

2- Determine the causes of lack breastfeeding among Saudi women at Hafr Al-Batin city.

Research questions:

- What are the practices of Saudi women regarding breast feeding?

- What are the factors influence breastfeeding practices among them?

\section{Research design}

Descriptive explanatory study design was used in this study.

\section{Methods}

The study was conducted in shopping malls where a large number of women can be recruited. A convenient purposeful sample of 193 Saudi women who attains for shopping at time of data collection was selected. Mothers who meeting the inclusion criteria of being aged from18-49 years and have at least one child less than 5 years were included in the study.

\section{Questionnaire:}

A structured interview questionnaire was developed and pretested to obtain information. It includes three parts of questions; the first part: to collect data bout socio-demographic characteristics such as age, work status, education level, income. The second part includes questions about the history of previous breastfeeding practices, colostrum feeding, and duration of breastfeeding, causes of lack breastfeeding and causes if discontinuing breastfeeding before 2 years child age. The third part gathered information about formula feeding use, complementary feeding starting time and food types.

\section{Pilot study:}

A pilot study was done on 20 respondents to test the clarity of the questionnaire.

\section{Ethical consideration:}

The purpose of the study was fully explained to the participants before starting interview. Verbal and written informed consent form was obtained from each study participant after assuring them about the confidentiality of information, and that data will be used for the research purpose.

\section{Data Analysis}

The data were organized, coded and analyzed using the Statistical package for Social Sciences (SPSS) version 20. Frequency and percentage distributions of sample characteristics were computed.

\section{Results}

Table (1) reveals that mean age of the study participants was $(33 \pm 5.73)$, More than half $(58.5 \%)$ were in the age group $(30-<40)$ and $70.5 \%$ of them had a university education. More than half $(63.2 \%)$ were working women, $(51.8 \%)$ of the study participants reported that their income was enough, while (44\%) reported that their income was enough and can be saved. The majorities $(89.6 \%)$ were multigravida, $(87 \%)$ were multiparous and less than three quarters $(72.0 \%)$ of the study participants had normal delivery. It was observed that $(23.8 \%)$ of the study respondents their youngest child aged (2- $<12$ months) and (73.6\%) aged more than one year. 
Table (1): Percentage distribution of the study participant's socio-demographic Characteristics

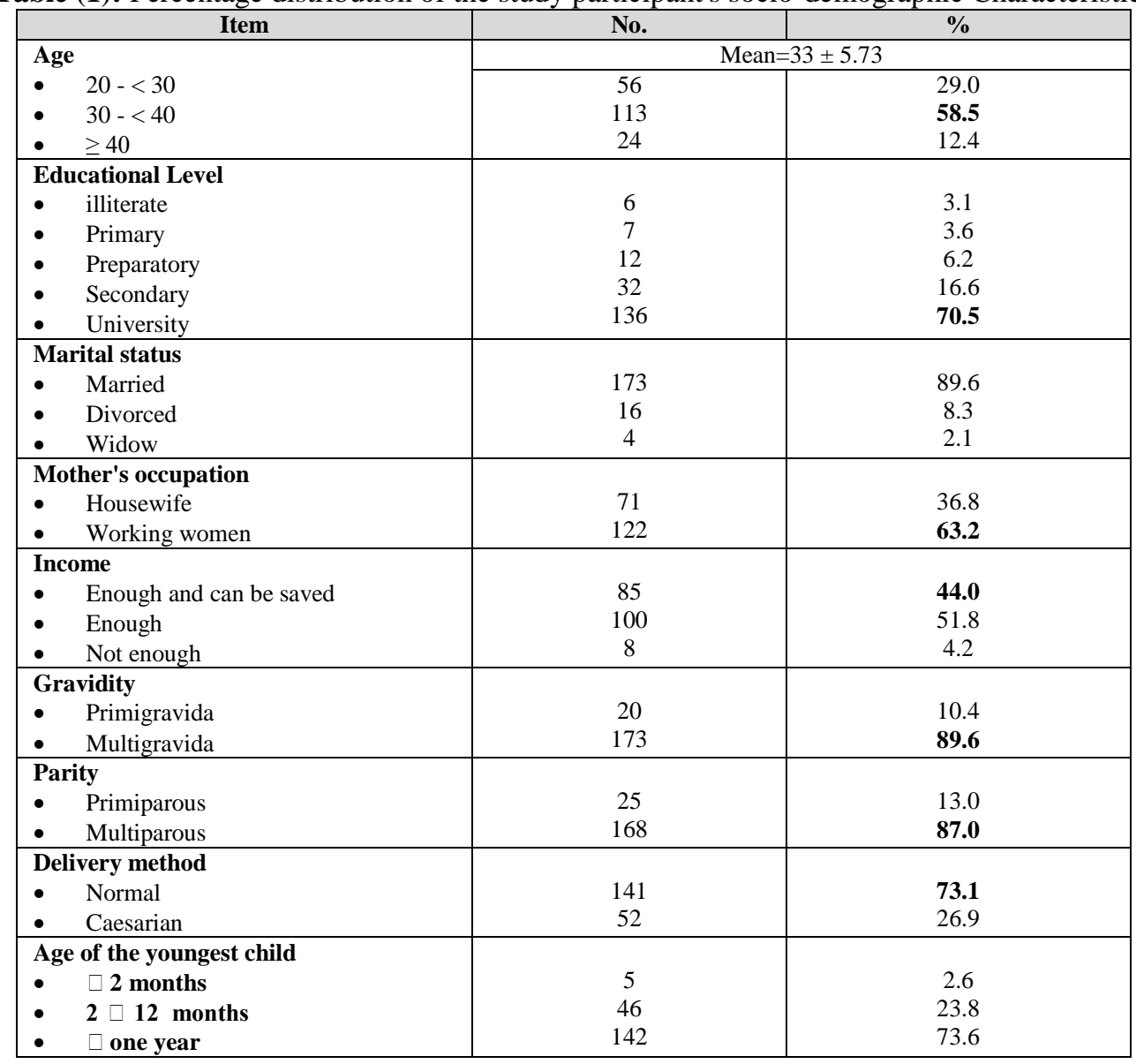

Table (2) shows that more than half $(52.3 \%)$ of the study respondents reported previously breastfed, $(52.5 \%)$ of them initiate breastfeeding early hours after delivery, while $(6.9 \%)$ of them initiate breastfeeding after one week. As regards to duration of breastfeeding, more than two thirds $(71.3 \%)$ of the study respondents reported breastfed their babies for less than six months. Mothers were asked about how they determine breastfeeding time, more than three quarters (76.2\%) reported breastfed their babies up on demand and (14.9\%) used a scheduled breast feeding time.

Table 2: Breastfeeding practices among study participants

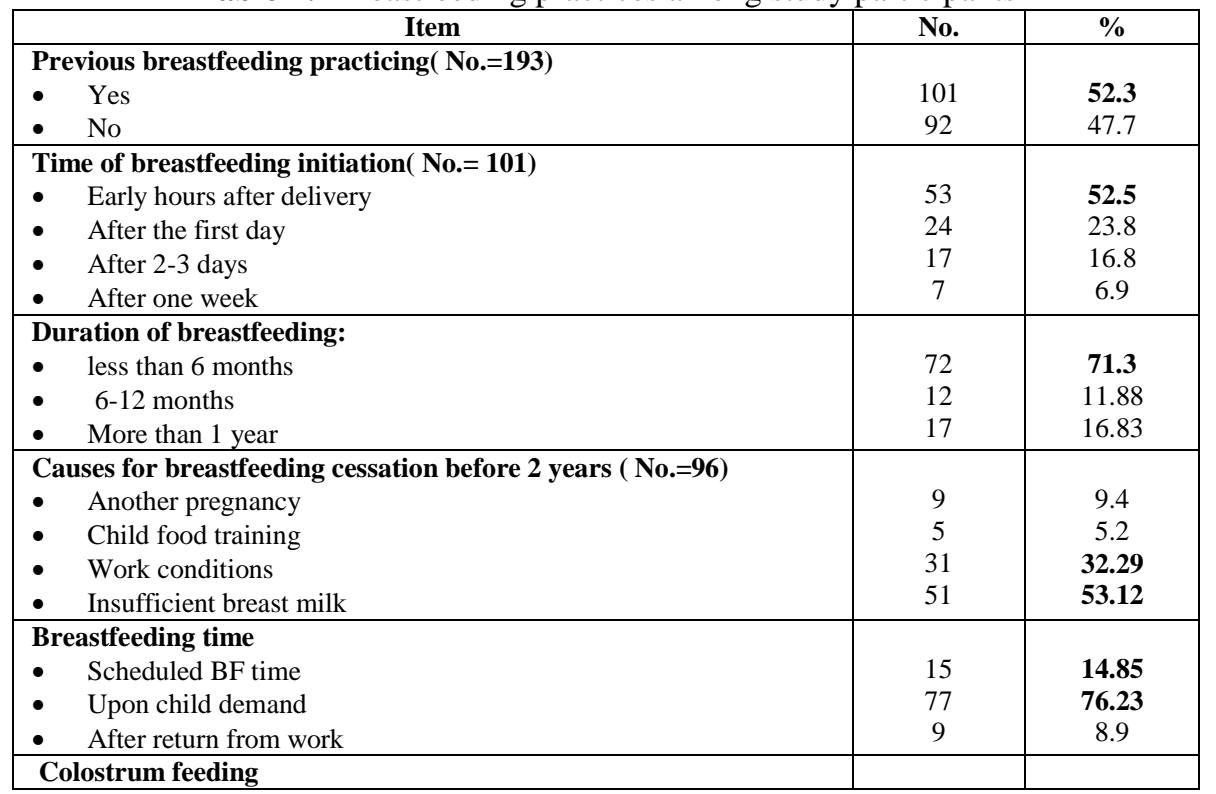




\begin{tabular}{|l|c|c|}
\hline - Yes & 71 & $\mathbf{7 0 . 3}$ \\
- No & 30 & 29.7 \\
\hline Causes for colostrum discarding No.= 30 & & \\
\hline - Not good for child health & 8 & $\mathbf{2 6 . 6}$ \\
- Child refuse breastfeeding & 9 & $\mathbf{3 0 . 0}$ \\
- Mother health causes & 9 & $\mathbf{3 0 . 0}$ \\
- Family/ friends advice & 4 & 13.4 \\
\hline
\end{tabular}

The results also revealed that more than two thirds (70.3\%) of breastfed women feed their babies the colostrum milk, while less than one third $(29.7 \%)$ discard it. The most frequent mentioned causes for discarding colostrum milk were child refuse, mother health problems, and believe that it is not useful for infant health $(30 \%, 30 \%, 26.6 \%)$, respectively.

Concerning the causes of lacking breast feeding, it was noticed that insufficient breast milk (49.5\%), pain or illness $(22.5 \%)$, job recruitment $(12.6 \%)$ breast problems $(6.3 \%)$, and cosmetic shape of breast/body (5.4\%) represents the most frequently mentioned causes by respondents for lacking breastfeeding. (Fig. 1)

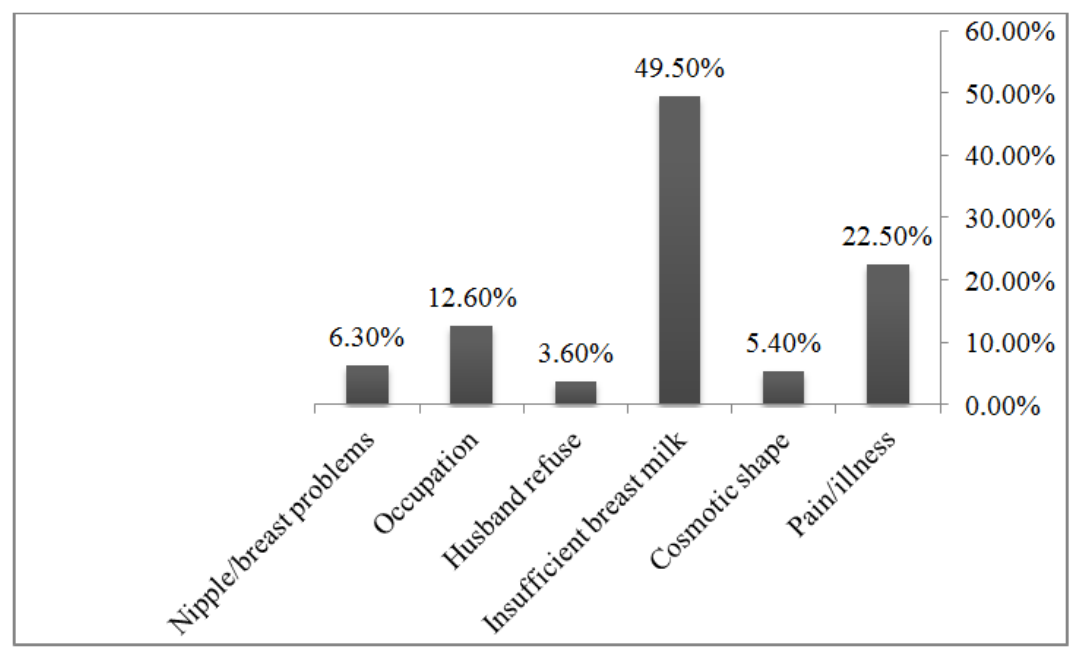

Figure 1. Causes for lack breastfeeding

Table (3) revealed the pattern of formula and complementary feeding by respondents, it was noticed that the majority $(93.8 \%)$ used formula feeding, while $(82.2 \%)$ of breastfed women use formula in conjunction with breastfeeding. On the other hand, (86.8\%) introduced supplementary food after the age of six months. As regards to supplementary food types, more than two thirds $(71.9 \%)$ started with ready-made cereals, $(23.3 \%)$ gave vegetables \& fruits and $(4.8 \%)$ gave rice \& macaroni.

Table (3): Formula \& complementary feeding pattern among study participants

\begin{tabular}{|c|c|c|}
\hline Variables & No. & $\%$ \\
\hline $\begin{array}{l}\text { Use of formula feeding }(\text { No. }=193) \\
\text { - Yes } \\
-\quad \text { No }\end{array}$ & $\begin{array}{l}181 \\
12\end{array}$ & $\begin{array}{l}93.7 \\
6.2\end{array}$ \\
\hline $\begin{array}{ll}* & \text { Causes for formula feeding use( No.=182) } \\
\text { - } & \text { To increase child weight } \\
\text { - } & \text { Insufficient breast milk } \\
\text { - } & \text { Work related conditions } \\
\text { - } & \text { Mother's health problems } \\
\end{array}$ & $\begin{array}{c}2 \\
106 \\
45 \\
29\end{array}$ & $\begin{array}{c}1.1 \\
58.3 \\
24.7 \\
15.9\end{array}$ \\
\hline $\begin{array}{l}\text { Mix feeding }(\text { No.=101) } \\
\text { - } \quad \text { Yes } \\
-\quad \text { No }\end{array}$ & $\begin{array}{l}83 \\
18\end{array}$ & $\begin{array}{l}82.18 \\
17.82\end{array}$ \\
\hline $\begin{array}{l}\text { Complementary food introduction( No.= 167) } \\
\text { - Yes } \\
-\quad \text { No }\end{array}$ & $\begin{array}{c}166 \\
15\end{array}$ & $\begin{array}{c}91.7 \\
8.3\end{array}$ \\
\hline $\begin{array}{l}\text { Time of complementary food starting } \\
\text { - } \quad \text { After } 6 \text { months of age } \\
\text { - } \quad \text { After the first year }\end{array}$ & $\begin{array}{c}145 \\
22\end{array}$ & $\begin{array}{l}86.8 \\
13.2\end{array}$ \\
\hline $\begin{array}{l}* \text { Types of complementary food } \\
\text { - } \quad \text { Ready cooked cereals } \\
\text { - } \quad \text { Vegetables/Fruits } \\
\text { - } \quad \text { Rice/Marconi }\end{array}$ & $\begin{array}{c}151 \\
49 \\
10\end{array}$ & $\begin{array}{c}71.9 \\
23.3 \\
4.8\end{array}$ \\
\hline
\end{tabular}




\section{* More than one answer was stated}

As shown in (table $2 \& 3$ ) the most common reported causes for breastfeeding cessation before 2 years age and use of formula feeding were insufficient breast milk and work related conditions.

\section{Discussion}

Breastfeeding is optimal method of infant feeding that provides many benefits to both mother and her infant. The monitoring of breastfeeding practices are essential for any society to plan and implement effective promotion programs for enhancing breastfeeding as well as enhancing women and child health.

WHO, 2011 recommended initiation of breast feeding within the first hours postpartum to enhance those infants receives the first milk and improve lactation and milk flow. The present study reveals that, more than half of breastfed mothers initiate feeding early hours after delivery. This may due to hospital practices including (rooming in), that help mother to fed baby within one hour after delivery. This finding also agree with that reported by (Adnan, 2014) who found that more than three quarters $(86 \%)$ of women received help from hospital staff for breast feeding immediate after delivery. Other support study findings reported by (Singh, 2012) that $(74 \%)$ of mothers initiated breast feeding within 6 hours. On the other hand (El- Gilany etal, 2011) reported that only $(11.4 \%)$ of mothers started breastfeeding within the first hour after delivery, while (Amin \& Hablas, 2011) found that $(77.8 \%)$ of studied mothers had initiated breastfeeding within 24 hours post-partum.

Saudi Arabia is a Muslim country and as mentioned in the Islamic teaching in the Holy Quran which states "And mothers shall breastfeed their children for two whole years, for those who desire to complete the appropriate duration of breastfeeding" (Al-Jassir etal, 2003). The parents may choose to stop earlier if the mother does not have the abilities to continue, or they may choose to hire the services of a wet nurse. Therefore, high breast feeding initiation rates are reported in numerousness national survey conducts in different regional of Saudi Arabia. (Aljuaid etal, 2014)

As regards to colostrum feeding, the present results showed that two-thirds of the respondents feed their babies the colostrum milk, while more than one quarter discards it. This finding was contrary to what was reported by Singh et al. in 1997, where $77 \%$ of mothers from the District of Rajasthan, India, discarded colostrum and to what has been reported recently from other parts of India, where 15 to $60 \%$ of studied women still discard colostrum (Patro etal, 2012 \& Bobhate \& Shrivastava, 2012).

The present results showed that more than two thirds $(71.3 \%)$ of the lactating mothers continued to breastfed their children for less than six months. This result similar to that reported by (Thomas, 2004 \& Jabarim, etal, 2015) who found that over all mother fed her baby for six months or early due to the mother thinking that their child was old enough and need to return to work. Various studies show that mean duration of breast feeding has decreased over the past 20 years this is hypothesized to be due to urbanization and change in socioeconomic statues so change in nutritional habits (El Gilany, 2011).

The present findings also revealed that the vast majority used formula feeding, this result agreed with that reported by Al-Binali 2012, that most of the participants shifted to formula feeding by six month $(91.7 \%)$. This practice might be attributed to the willingness of the mother to train their baby to use formula from a young age due to the pressures of work environments unsuitable for breastfeeding. Cunningham, 2011 reported that the availability of free formula and the easy access for using it while in hospital after birth was reported a reason for early introduction of formula.

Also, Amin \& Hablas, 2011, reported that due to change in socioeconomic statues and education level and employment opportunity, Saudi women are currently become more educated and undertake employment and they are become not accepting the motherhood role.

The current study results shows that the most mentioned causes for lack of breast feeding and uses of formula feeding were insufficient milk, work conditions, and pain or illness. These findings supported by ( Thulier \& Mercer 2009, and Nabulsi, 2011) who reported that breastfeeding influenced by maternal age, maternal employment, the level of education of parents, socioeconomic status, insufficient milk supply, infant health problems, method of delivery. This finding also supported by that reported by (Shahbar, 2014) that not enough milk, life style and work were the most common reasons for introducing formula.

Concerning complementary food, the majority of mothers stated introducing complementary food to their infants after the recommended age of 6 months. This finding was contrary to that reported by (Radwan, 2013 ) who found that $(83.5 \%)$ of mothers introduced solid foods to their infants before the recommended age of 6 months. The findings also revealed that more than two thirds of mothers started complementary food with ready- made cereals.

\section{Conclusion}

This study revealed that more than two thirds of study participant's breastfed their babies for less than 6 months, and the most mentioned causes for lack breastfeeding were insufficient milk and work related conditions in Hafr Al-Batin city, Saudi Arabia. 


\section{Recommendations}

1. Comprehensive programs taking advantage of the Quran advice on breastfeeding should be directed to mothers.

2. Building mothers confidence in their ability to produce enough milk and proper assessment of the infant's intake.

\section{Acknowledgment}

The authors gratefully acknowledge Asmaa Dahwy Al-Shamry for her cooperation and help in data collection period and also extend thanks for all participant women for their kind cooperation and participation.

\section{References}

[1]. Adnan, H. (2014). Breastfeeding knowledge, practices and attitude and influence factors .Thesis submitted in partial fulfill the requirements for the degree of master in community health. Bemidji, Minnesota

[2]. Al juaid D, Binns C. \& Giglia R. (2014): Breastfeeding in Saudi Arabia: a review International Breastfeeding Journal20149:1 DOI: $10.1186 / 1746-4358-9-1$

[3]. Al-Binali, A M. (2012): Breastfeeding knowledge, attitude and practice among school teachers in Abha female educational district, southwestern Saudi Arabia. International Breastfeeding Journal, 7:10

[4]. Al-Jassir M, Moizuddin SK, Al-Bashir B (2003): A review of some statistics on breastfeeding in Saudi Arabia. Nutr Health, 17(2):123-130.

[5]. Al-madani etal, (2010) Saudi mothers expected attitudes toward breast feeding. ICAN: infant, child and adolescentnutrition,2(3), 187-198

[6]. Al-moud, M. (2013). Breastfeeding Practice among Women Attending Primary Health Centers in Riyadh. J Family Community Med., 19-30.

[7]. Amin T, Hablas H. (2011) Determinants of initiation and exclusivity of breast feeding in al Hassa, Saudi Arabia. Breast feeding medicine, 6(2), 59-68

[8]. Balo NM, Shembesh NM, Singh R: Maternal characteristics and infant and young child feeding in Benghazi. East Mediterr Health J. 1996, 2 (3): 432-439.

[9]. Bamgboye, E., Alburno, K., \& Al-Nasser, N. (2011): A retrospective study of factors affecting breastfeeding practices in a rural community of Saudi Arabia. East Afr Med J, 174-80.

[10]. Binns C., Juaid, D., \& Giglia, R. (2014). Breastfeeding in Saudi Arabia: a review. Int Breastfeed J., 1-9.

[11]. Bobhate PS, Shrivastava SR (2012): Breastfeeding practices and factors associated with it: A cross sectional study among tribal women in Khardi Primary Health Centre, Thane, India. International Journal of Public Health Research, 2(1):115-121.

[12]. Cunningham, S., \& Jellife, D. (2011): Breastfeeding and health in the 1980s: a global epidemiological review. Journal of Pediatrics, 659-65.

[13]. El-Gilany A, Shady E, Helal R (2011): Exclusive breastfeeding in Al-Hassa, Saudi Arabia. Breastfeed Med., 6: $209-213$. 10.1089/bfm.2010.0085.

[14]. Harfouche JK (1982): Breast-feeding patterns: a review of studies in the Eastern Mediterranean Region., Alexandria: World Health Organization, Eastern Mediterranean Regional Office, EMRO Technical publications Series, No.4

[15]. Jabarim M., Al- Hussein K., Al-Sayed M., Al-Faris A., Al-Shaya A., and Al-Shehri H. (2015): Breastfeeding Practices among Employed Saudi Mothers; Med. J. Cairo Univ., Vol. 83, No. 1, December: 1159-1163.

[16]. Lancet (2013). In UNICEF. Breastfeeding. Available at http://www.unicef.org/nutrition/index_24824.htm Retrieved 30 December 2015.

[17]. Ministry of Health in the Kingdom of Saudi Arabia: The health statistical year book. Riyadh: MOH 2010

[18]. Musaiger AO (1995): Breastfeeding Patterns in the Arabian Gulf Countries. World Rev Nutr Diet., 78: 164-190.

[19]. Nabulsi, N. (2011): Why are breastfeeding rates low in Lebanon? A qualitative study. B.M.C. Pediatr., 11: 75.

[20]. Patro S, Nanda S, Sahu R (2012): Infant feeding practices of Paroja: A t ribal community of Orissa. Studies on Home and Community Science, 6(1):21-25

[21]. Radwan $H$ (2013): Patterns and determinants of breastfeeding and complementary feeding practices of Emirati Mothers in the United Arab Emirates, BMC Public Health201313:171

[22]. Shahbar A (2014): Factors associated with breast feeding in western of Saudi Arabia. Thesis of partial fulfillment of the requirement for the degree of master. Massey University: north New Zealand.

[23]. Singh MB, Haldiya KR, Lakshminarayan J (1997): Infant feeding and weaning practices in some semi-arid rural area of Rajsthan. $J$ Indian Med Assoc, 95(11):576-578.590

[24]. Singh, J. (2012). Breastfeeding practices among lactating mothers: Problems and prospects in a cross-sectional study. International Journal of Health \& Allied Sciences.1, (2):54-58

[25]. Thomas G. (2004), survey: www public health .org/ha

[26]. Thulier D. and Mercer J. (2009): Variables associated with breastfeeding duration. J. Obstet. Gynaecol. Neonatal.Nurs., 38 (3): 25968

[27]. United Nations Children Fund. (2008). Breastfeeding: impact on child survival and global situation. Retrieved from http://www.unicef.org/nutrition/index_24824.html

[28]. Wayna, J. (2006): breastfeeding Millar and heather Maclean. Health report ,16,(2):82-90

[29]. World Breastfeeding Trends Initiative (WBTi) (2012): Name of the Country: Kingdom of Saudi Arabia

[30]. World Health organization (2015). Nutrition: Exclusive breast feeding. Available http://www.who.int/nutrition/topics/exclusive breastfeeding/en/ retrieved October

[31]. World Health Organization, (2010): Saudi Arabia Country profile. http://apps.who.int/nutrition/landscape/report.aspx?iso=sau.

[32]. World Health Organization, (2011): Nutrition from global data on breast feeding. Available at: http://www.who,int/topics/breastfeeding/en

[33]. World Health Organization, (2012): breastfeeding. Retrieved from http://www.who,int/topics/breastfeeding/en 